\title{
LA MUJER-MADRE DE LEOPOLD SEDAR SENGHOR Y EL MATRIARCADO EN LA LITERATURA FRANCOFONA
}

\author{
Alder Senior Grant
}

\begin{abstract}
The main purpose of this article is to analyze the relationship that Léopold Sédar Senghour, contemporary poet from Senegal, holds with his mother throughout his work Poemes.
\end{abstract}

\footnotetext{
"We must find the African woman, origin of life, source of community, source of truth, god comme to earth".

Cynthia M. Garnett "Look at the lies see the truth" in African Commentary.
}

La mujer ocupa un lugar preponderante en el universo poético de Léopold Sédar Senghor. En su obra, ella ejerce una fascinante tiranía en los papeles cambiantes de madre, amiga, amante y musa. Sin embargo, es la dependencia del poeta ante esta presencia femenina y sus sentimientos ambivalentes, mientras aspira a la felicidad que encarna una mujer amada y venerada - su madre - lo que constituye los centros de interés de este estudio.

La literatura francófona se ha dado como misión la rehabilitación de la cultura y de la civilización negras, razón por la cual la exaltación del pasado, la glorificación de las tradiciones ancestrales eran necesarias a fin de afrontar los problemas que surgieron a raíz de los contactos entre negros y blancos, y particularmente el desarraigo y la pérdida de los valores auténticos del mundo negro.

Si echamos una mirada retrospectiva sobre la producción literaria negra de expresión francesa, se podrá fácilmente constatar que Senghor, como columna de la "Negritud", se ha constituído en el precursor de la restitución de la dignidad de su raza. Es así como Senghor ha servido como modelo para los otros escritores francófonos, quienes, habiendo igualmente vivido experiencias maravillosas y habiendo sido testigos de los prodigios y sacrificios de sus madres, se permitieron transmitir este cosmos y difundirlo, como reconocimiento a aquella quien por su importancia constituye la base de la familia y de la sociedad. 
En este artículo el énfasis será puesto en Senghor, mientras que cinco otros autores serán brevemente citados, con el fin de ver la presencia del matriarcado como tema de la literatura negra francófona.

El poeta Senghor es originario del Senegal, donde la mujer juega un papel primordial en la sociedad: ella figura en primer plano como madre. Aunque las influencias mixtas árabe-berebere, europea y nómada han, de alguna manera, debilitado esta preeminencia en el seno de su propia cultura; según el poeta más destacado de este país, es el carácter maternal de la mujer lo que la ha mantenido en esta posición de privilegio.

Asimismo, esta misma importancia le es atribuída a nivel de toda la civilización negra africana:

"La femme occupe en Afrique noire, la première place; y occupait la première place, car l'influence arabo-berbère, puis européenne, l'influence des civilisations nomades n'a cessé d'amoindrir son rôle... La femme, parce que 'permanente' de la famille et donneuse de vie, a été promue en source de force vitale et gardienne de la maison, c'est-à-dire du passé et garante de l'avenir classique" (Senghor 1966: 143).

La mujer-madre funciona entonces como centro familar vital (Meza 1973: 1). En esta civilización africana basada en un sistema de matriarcado, ella tiene la responsabilidad casi absoluta en lo que concierne a la educación de sus hijos. Ella vela igualmente para que las tradiciones ancestrales que le han sido legadas, sean retransmitidas de generación en generación. De allí los epítetos que le son atribuídos por este eminente poeta: dadora de vida, fuente de fuerza vital, guardiana de la casa y garante del porvenir (Senghor 1066: 143).

Esta veneración de la mujer-madre empieza desde la infancia de Léopold Sédar Senghor. El poeta pasa sus más tiernos años en su pueblo natal, Joal, luego vive en Djilor, a muy pocas leguas de Joal. Este es un período marcado por la autoridad materna y bajo la influencia de esta mujer y de su tío Walli Toko, el joven Léopold se familiariza con los elementos de la jungla tropical: la flora y la fauna africanas.

Lastimosamente, esta presencia tranquilizadora no dura. En 1913, a la edad de siete años, el futuro poeta se ve privado de ella. Afectado por esta repentina separación, él la conjurará convirtiéndose en varias ocasiones en ese niño protegido de su madre con todo el encanto que este recuerdo evoca.

El "Reino de la Infancia" no es más que la aspiración de Senghor a encontrar una vez más la protección de la madre. Durante los períodos más difíciles de su vida, sueña con ello. Allí buscará la paz y la calma de los cuales disfrutaba en otro tiempo. El poeta está sin embargo consciente de lo infructuoso de esta búsqueda.

Es conveniente recordar que la madre de Senghor está presente en las dos primeras colecciones de su obra Poèmes. Desaparecerá luego de sus últimos escritos. Esto puede explicarse por las tres razones siguientes: primeramente, él escribe las dos primeras colecciones en Francia, durante la Segunda Guerra Mundial, además su madre aún estaba con vida y finalmente ningún amor pasional lo ataba a alguna mujer en particular. 
En la primera parte de su obra, la imagen de su madre aparece con una gran fuerza. El poeta se aprovecha de ello para describir con erudición el ambiente tropical africano, y en especial el de su pueblo natal, Joal, y sus alrededores. Luego, la imagen de esta mujer envejecida, llena de ternura y de mansedumbre es ofrecida al lector, a través de una óptica completamente filial. En efecto, Senghor la evoca y la resucita tal cual él la veía en el pasado, tal como la entreve o tal como él desearía verla.

\section{La mujer-madre y el cuadro espacio-temporal}

No es una casualidad que durante la noche, el poeta y su madre evolucionen en una interacción total. Normalmente, es en este momento que una madre y sus hijos pueden gozar de su mutua compañía. Este acercamiento tiene lugar habitualmente a partir de la más tierna edad, primeramente mediante el arrullo de los bebés, luego a través de las canciones infantiles y finalmente por intermedio de los cuentos que permiten al niño dormirse apaciblemente.

Las costumbres africanas son particularmente propicias a este género de experiencias. Por ejemplo, durante el día, la madre se encarga de laborar en el campo y también de los trabajos domésticos en su hogar. Ella no dispone entonces más que de la noche para reunirse con sus hijos. A la caída de la noche, la figura de la madre llega a ser fuente y refugio de ternura, puerto de recibimiento y confidente de grandes penas.

Durante la infancia del poeta, las veladas familiares revestían un carácter casi solemne: era una especie de rito al cual él se acostumbró y que le hará falta cuando la separación madre-hijo llegará.

Esta relación madre-hijo en la noche, era muy importante y creaba una dependencia en el plano de los sentimientos. Es entonces natural que al poeta dominado por la emoción, melancólico y alejado de su madre, le aparezca esta mujer en una visión de ternura y de dulzura durante las largas horas nocturnas.

Todos los rasgos particulares de esta mujer amada son traspasadas a la noche. Es así como la dulzura y la ternura maternas se hacen eco en la noche africana. Esta noche se constituye en una amiga que participa con agrado en la felicidad de estos dos seres.

La noche es, de esta manera, testigo de esta felicidad y símbolo del contentamiento del poeta durante su infancia. Más tarde, cuando llegarán los años difíciles, la noche le traerá de nuevo la visión de su madre de tiempos pasados, con todas las características que la hacen ser $\tan$ apreciada por el poeta.

En "Que m'accompagnent Koras et Balafong", el poeta canta así a su madre:

"Nuit d'Afrique ma nuit noire, mystique et claire noire et brillante

Tu reposes accordée à la terre, tu es la terre et les collines harmonieuses.

ô Beauté classique qui n'es point angle, mais ligne élastique élégante élancée!

ô visage classique! depuis le front bombé sous la fôret de 
senteurs et les yeux larges obliques jusqu'à la baie gragracieuse du menton et

L'élan fougueux des collines jumelles!

Ô courbes du douceur visage mélodique!

Ô ma Lionne ma Beauté noire, ma Nuit noire ma Noire ma Nue! (Senghor 1974: 35).

Dicho poema escrito luego de la declaración de la Segunda Guerra Mundial (1939 1945) en Europa, presenta a un niño que se dirige a la noche, personificación poética de una mujer, sin duda alguna, su madre. Esta oscuridad que él casi diviniza, pierde su carácter banal; ya no se trata de cualquier noche, sino de aquella que posee todos los atributos que él otorgaría a su madre: dulzura, melodía, elegancia, gracia, misticismo y brillo.

La noche toma entonces, al menos en este poema, una dimensión feminizada y sustituye a la efigie materna. El poeta le dirige una súplica cual un niño pródigo que no ha olvidado el seno de su madre: se complace en recordar su condición de niño sometido a la protección tranquilizadora de aquella que él ama y venera.

Mediante esta imagen o personificación de la noche, la madre y la noche comparten el color sombrío, el cual es siempre realzado por el poeta: ambas poseen una belleza sin igual simbolizada por el color negro de la piel femenina y de las tinieblas.

En "Nuit de Sine", el poeta se dirige a su madre para decirle:

"C'est l'heure des étoiles et de la Nuit qui songe

S'accoude à cette colline de nuages, drapée dans son long pagne de lait.

Les toits des cases luisent tendrement. Que disent-ils si confidentiels, aux étoiles?

Dedans, le foyer s'éteint dans l'intimité d'odeurs âcres et douces" (Senghor 1974: 12).

La noche, una vez más, ocupa el primer plano como elemento temporal y mítico. Es apreciada por ser el tiempo de los murmullos, de la meditación, y más particularmente, de la tranquilidad y de la calma.

De la misma manera, este respeto y esta veneración por la noche son traducidos por el cese de toda actividad por parte de los seres humanos: cesan las risas, los contadores y las bailarinas y los coros se callan para que este cuadro refleje la paz, la armonía y el apaciguamiento. Todos los elementos están en concordancia con el carácter de la mujer-madre:

"Voici que décline la lune lasse vers son lit de mer étale

Voici que s'assoupissent les éclats de rire, que les conteurs eux-mêmes

Dodelinent de la tête comme l'enfant sur le dos de sa mère

Voici que les pieds des danseurs s'alourdissent, que s'alourdit la langue des choeurs alternés" (Senghor 1974: 12). 
Consecuentemente, el silencio nocturno favorece este cuadro de feliz entendimiento en donde el niño y la madre constituyen el centro de interés.

El cuadro espacial en el cual figura esta madre venerada y amada por el poeta se subdivide en tres tipos de ambientes o atmósferas. El primero es el real. Comprende el ambiente en donde esta mujer vivió toda su vida y en el cual el poeta pasó su infancia. El segundo se sitúa en Europa. Allí Senghor describe su angustia y su desconcierto. La presencia materna no es percibida en este segundo ambiente más que indirectamente, bajo la forma de dolorosas evanescencias; este ambiente llega a ser irreal. Finalmente, las fantasías a las cuales se entrega Senghor y su aspiración a reconstruir el "Reino de la Infancia" permiten visualizar el tercer ambiente, el interiorizado.

$\mathrm{Al}$ igual como ocurre con la noche, el retrato de esta mujer se emparenta con la naturaleza circundante. Se capta muy claramente una progresión en la presentación del cuadro temporal que concuerda plenamente con el espacial: el día se transforma en noche y los ruidos habituales del día se cambian por un silencio nocturno. El paso de la agitación diurna a la tranquilidad nocturna no se presenta como la oposición de dos corrientes adversas, sino como una continuación lógica. Todos los elementos de la naturaleza participan de una manera armoniosa en esta transición.

"Nuit de Sine" es el poema por excelencia en donde está plasmada la atmósfera hogareña que dominaba durante la infancia de Senghor. Se da una unión indisoluble entre la madre, el hijo y el ambiente. El paisaje que rodea a esta mujer corresponde en todo a su estado de ánimo revelando una atmósfera general de dulzura y de ternura.

"Femme, pose sur mon front tes mains balsamiques, tes mains douces plus que fourrure.

Là-haut les palmes balancées qui bruissent dans la haute brise nocturne

A peine. Pas même la chanson de nourrice.

Qu'il nous berce, le silence rythmé.

Ecoutons son chant, écoutons battre notre sang sombre, écoutons

Battre le pouls profond de l'Afrique dans la brume des villages perdus." (Senghor 1974: 12)

Primeramente, es necesario hacer notar que el silencio se hace cadencia. No se trata del ruido de los tambores que el niño conoce muy bien, sino de la comprensión recíproca entre hijo y madre. Estos dos seres sienten la misma emoción cuando se encuentran en este ambiente y pueden gozar juntos de esta atmósfera tan agradable.

Los personajes se pliegan silenciosamente a este cuadro ya que los niños se duermen apaciblemente y los contadores junto con las bailarinas y los coros enmudecen.

Luego el poeta describe con precisión el firmamento. Observa que los techos de las casas se comunican con las estrellas, tal como lo haría una esposa con su marido al regreso de las labores cotidianas. Compara también la dulzura de la luna con la de las manos balsámicas de su madre (Senghor 1974: 12). 
El perfume no está ausente de esta atmósfera. Se trata de los olores agrios y dulces típicos de las chozas africanas las cuales provienen de la nutrición y de los habitantes de dicha choza. La cabaña ahumada (Senghor 1974: 12) permite adivinar la actividad, representada en especial, por el trabajo de la madre y la enorme responsabilidad que le toca en cuanto a la educación de sus hijos.

En el exterior de la cabaña, las palmas que murmuran completan el paisaje y favorecen el paso de los seres y de los objetos de la agitada vida diurna al apacible sueño nocturno.

Esta descripción comprende todos los aspectos de la naturaleza. Tiende a realzar el carácter agradable de la atmósfera y da la impresión de que la naturaleza se inclina ante esta dama y su hijo haciendo la reverencia. Este ambiente externo murmura tiernamente para no interrumpir este momento de paz del cual goza este niño en compañía de su madre.

El poeta y su madre se quedan de esta manera solos en presencia de las ánimas y en medio del perfume típico de las chozas. El autor nos precisa, en el epílogo de las Ethiopiques que dichas ánimas son los ancestros (Senghor 1974: 158). Esta era la atmósfera de la cual gozaban juntos, madre e hijo, durante los breves años de su infancia en su pueblo natal, Joal.

$\mathrm{Y}$ es solamente en la intimidad de este ambiente que el poeta se dirige a su madre. Le pide posar sus manos balsámicas sobre su frente, unas manos más dulces que "piel de abrigo". El contacto físico alivia así al niño quien puede entonces soñar sin tener nada que temer.

El segundo cuadro en el cual se desarrolla el trama configura a la Europa de la pre-guerra y de la Segunda Guerra Mundial. Para el poeta, este mundo es real mientras que su madre pertenece al mundo de lo imaginario. En efecto, en esta parte de la obra, y a pesar de que su evocación no es más que sugerida, el lector tiene la impresión de que ella está presente.

Luego, siempre dentro del mismo cuadro, el poeta evoca la belleza de la selva africana, tal como la conoció en el pasado. Si el segundo cuadro revela confusión y tristeza en Senghor, el primero y el tercero, al contrario, lo introducen en un mundo de mágica calma.

Efectivamente, cuando el escritor se encuentra alejado del hogar materno sufriendo severas crisis, llega a inquietarse en exceso. Este estado de ánimo del poeta entra en un contacto estrecho con un medio ambiente seco, desprovisto de amor y de ternura. Es por esta razón que hace intervenir a su madre, ya sea dialogando con ella, o bien monologando.

La mayor parte del tiempo ella está allí cerca de él y le escucha. Sin embargo, cuando ella no puede comprenderle, su presencia espiritual basta para reconfortarle. El tercer cuadro aparece entonces: Senghor, dejándose llevar por sus fantasías, vuelve a vislumbrar su "Reino de la Infancia", ese mundo de felicidad que se sobrepone a su estado de ánimo del momento.

En fin, aún si su madre esta físicamente ausente, ella se encuentra, sin embargo, presente en él. Ella se constituye en ese sedante, siempre lista para devolverle la paz interior que le hace falta para poder atravezar los períodos difíciles y para sobrellevar sus estados de crisis.

Una de las pruebas más duras para el poeta fue la guerra en Europa. En esa época, Senghor vivió en Francia, y sin quererlo se encuentra immerso en el conflicto bélico. Ante el cuadro de horror que se desarrolla en dicho escenario, la imagen de su querida madre regresa a su mente. La fuente de este recuerdo es una carta de un amigo que le envía noticias acerca de su tierra natal y de su familia. Senghor medita en el hecho de que su madre, a la edad de sesenta y tres años, se encuentra en el crepúsculo de su vida. El poeta, cual un niño, se dirige a ella para quejarse de su presente situación. 
En "Ndéssé", el poeta llegará inclusive a confesarle a su madre que no se había expresado en términos de verdad acerca de la existencia que lleva en Europa:

"Ah! me pèse le fardeau pieux de mon mensonge

Je ne suis plus le fonctionnaire qui a autorité, le marabout aux disciples charmés.

L'Europe m'a broyé comme le plat guerrier sous les pattes pachydermes des tanks" (Senghor 1974: 79).

Sensaciones de horror y una obsesión de destrucción asfixian su ser y oscurecen su espíritu. La realidad es percibida como una fuente de amenazas.

En "Liberation", Senghor prisionero de guerra en ese momento, se deja invadir por la desesperación. En este poema, el poeta no habla de su madre sino que recurre a una comparación relacionada con su infancia y que evoca a la madre ausente: "J'étais la me cognant la tête comme le désespoir d'un enfant nerveux" (Senghor 1974: 25).

Estos versos sugieren el desorden y el desamparo del huérfano, quien no recibe ayuda alguna, ningún sostén que le aliente para soportar todos los males que le aquejan. Este niño que no conoce ni la paz ni la tranquilidad, quien sufre por la ausencia del seno materno, se siente solo e impotente. Es un ser endeble y adolorido quien resiente la ausencia de un ser que lo apacigue y lo consuele.

Siempre en "Liberation", Senghor describe el tormento de su alma extraviada en este universo hostil:

"Les torrents de mon sang sifflaient le long des berges de ma cellule.

C'était pendant des nuits et des jours plus solitaires que la nuit." (Senghor 1974: 25).

La noche constituye para Senghor el cuadro temporal propicio para rumiar sus pensamientos y para volver a encontrar la calma (Senghor 1974: 80). Prisionero de los alemanes en ese momento, aprovecha el tiempo para elaborar un recapitulativo, un resumen, en donde recuerda los nueve años que vivió en Europa, lejos del seno materno.

El poeta cae entonces en las profundidades de la angustia, pero vuelve a divisar el rostro de su madre y escucha su voz: "J'entends ta voix quand je suis livré au silence sournois de cette nuit d'Europe" (Senghor 1974: 55). Este resurgimiento lo invita a fantasear y desemboca en el tercer cuadro, el del recogimiento interno.

La madre del poeta, como es de esperar en todo ser humano, revela humores diversos según las circunstancias que la rodean. De esta manera, su rostro transluce a veces una mirada alegre, y en otras ocasiones es triste y hasta rencorosa. En esta restitución del más allá, la primera imagen que tiene de su madre es aquella en donde la voz y los ojos parecen sumamente irritados (Senghor 1974: 55). ¿De dónde proviene esta nueva impresión? A sabiendas de que su madre está enojada por su partida, se supone que Senghor siente remordimientos hacia ella. En fin, el poeta trata de atenuar la gravedad de su falta y de obtener su perdón. Es- 
ta aparición mental del rostro femenino traduce la angustia y el pánico que se han apoderado de él. En lugar de percibir la tranquilidad en esta mujer, descubre una creatura transformada, una fuente de culpabilidad.

Este recuerdo vuelve al poeta cuando en Europa él se siente desamparado: "Je ne suis plus qu'un enfant qui se souvient de ton sein maternel et qui pleure" (Senghor 1974: 80). Su madre le hace falta, al igual que los paisajes y ese ambiente particular del continente africano. Es solamente al final de "Joal" que estos recuerdos son introducidos; antes, el poeta ha presentado los elementos exteriores con su brillo y todo lo que tienen de típicamente joalianos o africanos; es entonces natural que prosiga con todo lo que toca a los sentimientos. Al evocar en este poema la atmósfera de su pueblo, él descubre y expresa su pena.

El ritmo de las procesiones y de las ceremonias en Joal regresa con una fuerza casi dramática, zumba en su cabeza y lo sumerge en sus recuerdos. No obstante, la alegría de este ritmo se transforma - estando en París - en un movimiento triste, lleno de pena que se traduce por el jazz.

Esta música que él llama "jazz huérfano" no tiene nada de melodioso; languidece al poeta cuyo espíritu se marchita en la soledad. Le permite igualmente soñar con su tierra natal, una fantasía verleniana, triste, y con el cansancio que resulta de los numerosos sollozos. Dichos sollozos son provocados por un deseo, cuya naturaleza es a la vez sentimental y espiritual; a falta de poder tocar a la madre amada y de poder pisar el suelo natal, al poeta no le queda más recurso que el de un pensamiento tierno y al mismo tiempo, llorar de despecho y de vergüenza.

Por otra parte, el poeta siente ante esta madre una nostalgia y muchos remordimientos los cuales son dramatizados en la última estrofa de "Ndéssé". El se siente cortado de ella e impotente en su afán por servirle de apoyo:

"Je devais être, Mère le palmier florissant de ta vieillesse,

je te voudrais rendre l'ivresse de tes jeunes années.

Je ne suis plus que ton enfant endolori, et il se tourne et retourne sur ses flancs douloureux..." (Senghor 1974: 80)

Ante su madre, Senghor no ha crecido nunca, ni crecerá jamás, lo cual él acepta. El aspira a revivir una vez más ese bello "Reino de la Infancia", rodeado del encanto que le asegura la presencia materna durante la noche.

En este punto, su madre está aún físicamente ausente; su presencia espiritual es sin embargo saciada por la consciencia personal del poeta y atenúa milagrosamente su angustia. Su soledad es menos sentida aun si el poder bienhechor del contacto físico le siga haciendo falta.

En "Ndéssé", Senghor retoma la descripción de la jungla africana, de las fiestas atléticas, de las mies y de las palmeras. Este tercer cuadro se opone al segundo: su madre envejece en medio de esta atmósfera, mientras que el poeta indefenso, rodeado de tanques y de tiros de fusil no puede estar cerca de ella (Senghor 1974: 80).

Su triste y dolorosa condición de prisionero le impide cumplir este deseo. No le queda más que la aspiración a gozar una vez más de esa noche africana, aclarada por la mirada reconfortante de su madre, la sensación de proximidad del seno materno y el recuerdo de las veladas de cuentos (Senghor 1974: 80). En fin, este retorno al "Reino de la Infancia" le permite volver a 
encontrar el orgullo legado por sus padres y "borrar la humillación de ser un soldado prisionero" (Senghor 1974: 80).

Cuando emprende su segundo viaje a Europa, el poeta exclama en "Le Retour de l'enfant prodigue":

"Ah! de nouveau dormir dans le lit frais de mon enfance

Ah! bordent de nouveau mon sommeil les si chères mains noires

Et de nouveau le blanc sourire de ma mère

Demain, je reprendrai le chemin de l'Europe, chemin de l'ambassade

Dans le regret du Pays noir" (Senghor 1974: 50)

En estos versos, él vuelve a crear el solaz que su madre le procuraba. Al mismo tiempo, su lejana infancia despierta el dolor en él. Además evoca la paz, la dulzura del sueño y el alivio que suscitaba en él, el contacto de las manos negras. El cuadro reactualizado se concretiza, se visualiza y afecta al poeta en una especie de psicodrama.

Finalmente, vuelve al camino de los honores en Francia, puesto que en 1945 es elegido diputado de los electores africanos ante la Asamblea Nacional de la Metrópoli. Es reelecto en 1946, haciendo alusión a ello en "Le Retour de l'enfant prodigue" (Senghor 1974: 50). Sin embargo, no puede olvidar la angustia ocasionada por la separación de su madre. Ella es ahora una vieja mujer a quien le gustaría que su hijo estuviese cerca de ella durante los últimos días de su vida.

Se constata entonces que este tercer cuadro espacial no es más que la reaparición memorial del primero, pero dispuesto en otra perspectiva, la de una percepción sensibilizada por la imagen afectiva de la separación. Se opone al segundo cuadro que es la Europa de la Segunda Guerra Mundial.

De esta manera, el poeta conserva la confluencia imaginaria deseada y sentida como necesaria con su madre durante sus "extravíos" a través del viejo continente.

\section{Relaciones madre-hijo}

El hijo se esfuerza por no perder su condición de niño. Además, él considera que no la ha perdido nunca. Las experiencias, buenas y malas, vividas en Europa no han bastado para arrebatarle su alma infantil. Al contrario, le han hecho adherirse aún más a este rasgo.

En "Que m'accopagnent Koras et Balafong", se dirige a la noche que personifica a su madre:

\footnotetext{
"Nuit qui fonds toutes mes contradictions, toutes contradictions dans l'unité première de ta négritude

Reçois l'enfant toujours enfant, que douze ans d'errances n'ont pas vieilli." (Senghor 1974: 35)
} 
Este sentimiento es más fuerte que él: el poeta quiere continuar siendo un niño ya que de esta manera está obligado a pensar en su madre, verdadera representación de seguridad, protección, ternura y amor.

Su estadía en Europa significa para él doce años de extravíos. Se imagina siendo un niño que escapa de su hogar, que vaga por el mundo, y luego cansado de esta vagabundería, decide regresar bajo las alas de una madre siempre dispuesta a recibir y garantizar a su progenitura contra todas las agresiones del exterior.

El entendimiento entre el poeta y su madre no es siempre perfecto. En ".A l'appel de la race de Saba", Senghor confiesa que no logran siempre comunicarse entre ellos: "Tu ne m'entends pas quand je t'entends, telle la mère anxieuse qui oublie de presser le bouton du téléphone" (Senghor 1974: 56). No es que esta relación se juzgue imposible, sino todo lo contrario. La ansiedad provocada por la separación impide, sin embargo, que la vieja madre oiga la voz emocionada de su hijo.

Completamente al final de este poema, el poeta reclama el reconocimiento para sus compañeros que han compartido su destino. Con este hecho, universaliza y diviniza la figura de su madre. Mediante una bella transparencia metaforizada, deja aparecer un destello de esperanza: "elle doit dans le crépuscule de sa vieillesse saluer l'aube transparente d'un jour nouveau" (Senghor 1974: 60).

La mirada materna es esencial para la descripción o la evocación de las relaciones madre-hijo. Sirve para mejor descubrir y comprender a la madre de Senghor. Los ojos de esta mujer le permiten al poeta exorcisar sus miedos y sus angustias y volver a encontrar la protección y la seguridad que necesita frente a la situación tan crítica que debe afrontar.

En "Ndéssé" el poeta se acuerda de sus veladas en el transcurso de las cuales el poder y la magia de la mirada materna le devolvían la confianza. Es por ello que implora piadosamente: "Reçois-moi dans la nuit qu'éclaire l'assurance de ton regard" (Senghor 1974: 80).

El escritor reconstituye otra visión durante los momentos particularmente difíciles de su vida: la de esta mujer descontenta cuyos ojos proyectaban un brillo de salvaje incendio bajo los efectos de la cólera. Este efecto permite adivinar que su hijo está asediado por los remordimientos y que no puede calmar su consciencia: "Voila des yeux courroucés et rouges qui incendient nuit et brousse noire comme au jour jadis de mes fugues" (Senghor 1974: 55). En tiempos pasados este enojo transfiguraba su rostro. Ella aparecía ofendida: "Et tremblait ton menton sous tes lèvres gonflées et tordues" (Senghor 1974: 55). De esta manera es como el poeta la veía y la volvía a visualizar cuando no tenía la consciencia tranquila.

Otro aspecto importante que caracteriza a la madre de Senghor es la dulzura de su voz. Se acostumbró a oirla desde los primeros días de su existencia mediante el arrullo y más adelante, durante la narración de los cuentos a la hora de las veladas. Es por eso que en "Ndéssé", él le ruega que le haga escuchar una vez más su voz: "Redis-moi les vieux contes des veillées noires, que je me perde par les routes sans mémoire" (Senghor 1974: 80).

Las dificultades de la vida, aumentadas por el desarrollo de la guerra y por los sufrimientos que causa, han transformado el tono de la voz de este hombre:

"Mère, parle-moi. Ma langue glisse sur nos mots sonores et durs. 
Tu les sais faire doux et moelleux comme à ton fils chéri autrefois." (Senghor 1974: 79).

En el silencio siniestro de la noche europea, el poeta percibe igualmente un cambio de tono en la voz materna. Contrariamente a sus deseos, la voz materna está irritada. Ella denuncia la actitud de su hijo y el abandono del cual ella ha sido objeto:

"J'entends ta voix quand je suis livré au silence sournois

de cette nuit d'Europe

Mère, Oh! j'entends ta voix courroucée." (Senghor 1974: 79)

Todo esto permite descubrir a una mujer de fisionomía animada y expresiva. Su mirada y su voz, según el grado de equilibrio interior, pasan de la dulzura al rencor e inversamente. Esta búsqueda de los antiguos lazos entre una madre y su hijo es entonces a veces dolorosa. La figura femenina de la madre adquiere una nueva vocación: ya no es un simple elemento consolador, puesto que ella llega a ser un elemento pertubador que provoca las lágrimas de su hijo o que hace brotar las suyas propias.

En "A l'appel de la race de Saba" su hijo comparece ante ella como un renegado. De alguna manera, él ha rechazado todos los principios que ella le había inculcado, ha negado la cultura africana y a su propia familia para ir a defender la causa de los Franceses en Europa. Para ella, la noche es justamente el momento propicio para evocar a su querido hijo y para llorar su ausencia y el olvido de su pacto.

"Mère, tu pleures les transfuge à l'heure de faiblesse qui précede

le sommeil, que l'on a verrouillé les portes et qu'aboient

les chiens jeunes aux Esprits" (Senghor 1974: 57).

Finalmente, hay que subrayar el hecho de que ante su madre, el poeta siente respeto y devoción filiales. El desea ardientemente regresar al "Reino de la Infancia" para sentirse protegido, tranquilizado y amado por aquella que fue la primera mujer de su vida. Además, él puede confiarle los secretos de su alma que no se atreve a confesar a otras mujeres.

Sin duda alguna, la madre de Senghor fue una mujer muy bella. No se trata de belleza física, la cual el poeta no alude y de la cual ignoramos prácticamente todo. Se trata más bien de una belleza interior que nació de los años de sacrificio que ella soportó sin jamás quejarse. Basta con que sus manos sean balsámicas y dulces, que su mirada esté llena de bondad y que las inflexiones de su voz sean dulces y tiernas para que su benévola influencia acompañe al poeta por el tiempo que la fantasía de éste la haga surgir de su espesura cósmica. Al final de cuentas, la mansedumbre, el afecto y la comprensión caracterizan a esta mujer.

La madre de Senghor funciona igualmente como una fuente de unidad psíquica y cósmica. El ensueño y la habilidad para hacer aparecer a esta figura amada de un espacio afectivo, salva a su hijo de sus pesadillas nocturnas. Su soledad, sus expectativas y sus quejas nostálgicas son conjurados de esta manera. Apoyándose en esta relación íntima, el universo senghoriano encuentra en parte su relieve y orientación. 


\section{La herencia de Senghor a la cultura negra francófona}

La pregunta que se impone es si Senghor constituye un caso aislado, excepcional dentro de la literatura negra francófona y si ha sido el único en glorificar a la mujer-madre. Algunos pocos ejemplos bastarán para demostrar que otros autores francófonos retomaron este tema en sus escritos. Este aporte viene a completar y a reforzar el retrato de esta mujer-madre como centro vital de su familia.

Es a manera de conclusión, y por lo tanto muy brevemente, que estos otros autores serán citados: cuatro escritores africanos y un antillano francófono.

Empezaremos por el camerunés Mongo Beti, quien describe en sus novelas el orden social y cultural que reinaban en los pueblos de su infancia y en donde la madre ocupa el primer lugar en la jerarquía familiar. En Mission Terminée, el autor presenta las costumbres camerunenses en cuanto al adulterio. Esta falta grave contra la moral pública, unánimemente condenada en todas las culturas, es sin embargo perdonada, en Camerún, si el pecado es cometido por una mujer-madre:

"La prévention de ma mère à l'endroit de la femme Niam s'expliquait surtout par le fait que l'épouse de mon cousin, après des années de mariage, et d'une façon incompréhensible n'avait pas eu d'enfants: c'est le sort commun de chez nous à toutes les épouses sans enfant d'être en butte à un étrange anathème dont il faut chercher l'origine dans la métaphysique de nos pères bantous. Une épouse mère, elle, se voit pardonner toutes ses infidélités, tous ses caprices." (Mongo Beti citado por Normann-Seiler 1976: 69).

La fecundidad-maternidad salva entonces a la mujer del Camerún de la maldición de la sociedad, reforzando su posición. Y es gracias al respeto por las tradiciones ancestrales que el estatus privilegiado de la mujer-madre permanece inquebrantable.

A pesar de que Senghor no tocó el tema de la infidelidad en la mujer-madre, se puede sin embargo suponer que este aspecto no haría tambalear la posición dirigente de esta mujer en la sociedad senegalesa, puesto que ello implicaría un ataque directo a la "dadora de vida y fuente de fuerza y vital" y en consecuencia a toda la estructura o fundamento de la familia en el Senegal.

Continuamos con Camara Laye, autor africano originario de Guinea. En su novela autobiográfica L'Enfant noir, él también trata el tema de la glorificación y mistificación de la mujer-madre. Ella no es solamente importante para el equilibrio psíquico y social de toda la familia, sino que posee además ciertos poderes sobrenaturales. Aun si la narración de las proezas de su madre lleguen a provocar el escepticismo en algunos lectores, Camara Laye osa contar algunos episodios extraordinarios vividos durante su niñez y de los cuales citaremos tres:

a) la madre, quien ha heredado el cocodrilo como totem del abuelo materno de Camara, se permitía desafiar a estos voraces animales, manteniéndose cerca de ellos en el agua sin temerles. Al entrar en un río, ella estaba protegida contra cualquier tipo de mal que podría sucederle.

b) un caballo que se obstinaba en no querer levantarse, a pesar de los esfuerzos de su propietario, lo hizo de inmediato al escuchar la voz autoritaria de la madre de Camara Laye. 
c) la madre de Camara Laye poseía un extraño don de magia que le permitía detectar la maldad que se tramaba y denunciar al culpable. (Laye 1953: 66 a 70)

No debe entonces sorprender el hecho de que el marido de esta extraordinaria mujer ceda la autoridad a la madre. El papel sin igual que le era atribuído en el seno de la familia es subrayado por el autor cuando nos dice: "qu'ayant achevé son repas, il remerciait son père, mais s'inclinait devant sa mère lui faisant savoir que le repas était bon" (Laye 1953: 65). El respeto que Camara le tenía era evidente y el hecho de inclinarse ante ella y no ante su padre, confería a esta madre excepcional, además del agradecimiento y la admiración, el primer rango. De esta manera se le proclamaba jefe indiscutible de su clan.

Al aparecer, en 1953, L'Enfant noir, la publicación traía una dedicatoria, en donde Camara Laye, con un tono exaltado, lleno de lirismo, reconocía los méritos de su madre, utilizando una estética negro-africana. El autor se lamentaba por no poder ser más un niño rodeado del afecto materno:

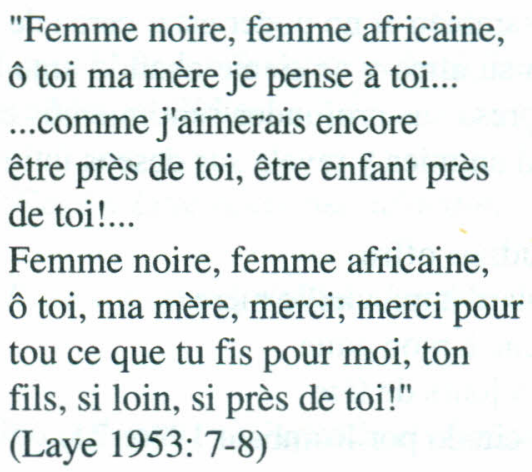

La musicalidad de este poema está traducida por el ritmo completamente africano de los tambores: utilizando las formas de letanías, Camara Laye hace resonar los latidos de su corazón en armonía total con el ritmo del poema, lo cual nos recuerda a Senghor en su célebre poema "Femme noire" (Senghor 1974: 14-15).

Otro africano, Abdoulaye Mamani, originario del Níger, canta su desesperación y angustia ante su condición de asimilado. Al igual que Senghor cuando se encuentra ante situaciones de apremio o de crisis interior, Mamani viene a quejarse naturalmente a su madre. Con un tono franco, lleno de amargura, lanza un grito de protesta en su poema "Civilisé":

\author{
"Maintenant il me faut porter \\ la jaquette de laine \\ un bout de torchon \\ autour de mon cou \\ transpirer dans une chemise Nylon \\ Et ce gilet de soie qui m'etouffe \\ Ah! ma mère, quel supplice! \\ souffir mille douleurs
}


cent cors me rongent les pieds

prisonniers des souliers bouts-pointus."

(Mamani citado por Rombaut 1976: 114)

Una amarga ironía acompaña a esta queja, Sin embargo, el lector no percibe la reacción de su madre, contrariamente a lo que ocurre en los escritos de Senghor en donde el poeta presentaba y describía con todo detalle las respuestas de su madre a su angustioso llamado (Senghor 1974: 55 a 60). No es pues una coincidencia si Mamani, imitando a Senghor, regrese a su "Reino de la Infancia" para tratar de encontrar a la madre y confiar en ella, con el fin de liberar su alma del peso de ese tormento que lo aplastaba. Ninguna otra persona sabría comprenderlo, nadie más podría procurarle el alivio que necesitaba para calmar su alma torturada. La magnitud de la injusticia de los cambios que le son impuestos por una cultura que le es completamente ajena, hace que el autor dirija esta súplica a su madre.

Otro escritor francófono que trata el tema de la mujer-madre es Bernard Dadié. Este poeta de Costa de Marfil lamenta también el no poder estar cerca de su madre. Está desecho por los remordimientos que carcomen su alma y se siente abatido ante su presente impotencia. De la misma manera que Senghor expresa sus profundos sentimientos en "Ndéssé" (Senghor 1974: 79-80), Dadié subraya su debilidad anímica y revela sus deseos íntimos:

"Je voudrais offrir

Un foulard à ma vieille mère

Un pagne à mon amie

Pour les jours de fête"

(Dadié citado por Rombaut 1976: 74)

Durante los momentos de crisis, cuando el alma está confusa, el recuerdo de la vieja madre abandonada regresa siempre para atormentar a estos escritores. El deseo vehemente de reparar esta falta los obliga siempre a confesar lo que harían para recompensar a la madre amada y venerada.

Finalmente, en esta misma corriente se inscriben las palabras del haitiano Gérard Chenet, cuando declara su agradecimiento a la mujer que se hizo hombre para cumplir con su sagrada misión siendo padre y madre a la vez: "Ayant dû ma naissance à la femme qui s'est faite homme pour à elle seule m'accomplir" (Chenet citado por Rombaut 1976: 258).

El papel jugado por la madre de Chenet es doblemente meritorio, ya que a causa de la situación económica, política y social en Haití, ella se ve obligada a soportar todas las dificultades que acarrea su condición de madre soltera.

Aun cuando no fuese más que parcialmente, todos estos autores francófonos han esbozado a su manera la pintura de un universo diferente, de un mundo en donde la figura de la mujer-madre reclama y obtiene la posición preponderante que le es debida. También contribuyeron a perpetuar una parte importante de sus tradiciones ancestrales.

Es así como Senghor y sus colegas francófonos han logrado hacer el retrato de la mujer-madre. Se trata de la representación de todas las madres negras que cumplen con una tarea 
tradicional muy importante: la responsabilidad de la procreación y la educación de sus hijos, responsabilidad que origina el matriarcado reinante en el universo negro-africano.

En la hora actual, cuando las corrientes de modernización parecen amenazar ciertos principios de la civilización y cultura negras - africana y antillana - es necesario hacer votos para que la mujer-madre continúe manteniendo su posición privilegiada. Las creencias, la ética y estética de este mundo tan particular, la riqueza de sus tradiciones milenarias y de sus valores socio-culturales deberán contribuir a consolidar este estatus-quo y las mujeres-madres de los escritores francófonos negros continuarán a inspirar la pluma de sus progenituras.

\section{Bibliografía}

Chévrier, Jacques. 1974. Littérature nègre. Paris: Librairie Armand Colin.

Laye, Camara. 1953. L'Enfant noir. Paris: Plon.

Mezu, Okechukwu. 1968. Léopold Sédar Senghor et la défense et illustration de la civilisation noire. Paris: Librairie Marcel Didier,

Nordmann-Seiler, Almut. 1976. La Littérature neo-africaine. Paris: PUF.

Rombaut, Marc. 1976. La Poésie négro-africaine d'expression française. Paris: Editions Seghers.

Sédar Senghor, Leopold. 1966. Liberté 1: Négritude et Humanisme. Paris: PUF.

1973. Poèmes. París: Editions du Seuil. 
